\title{
Yaneura - The Attic
}

Adam Broinowski

The University of Melbourne

\section{Introduction}

While at Shizuoka University as an undergraduate exchange student, I began my involvement in theatre by learning Noh (Kanze school) from Professor Ueda-Munakata, a specialist in adapting and producing Shakespeare's plays in Noh style. After touring to Australia with him, I remained to write plays, perform with many theatre companies both in Australia and internationally (in styles ranging from acrobatics, dance, clown, physical theatre, realism and multi-media performance), direct productions, create installations and make a documentary on Japanese sub-cultures ${ }^{1}$. In 2001, upon receipt of a Japan Foundation artist's fellowship, I returned to Japan to research avant-garde theatre. I was invited to become a core member of Gekidan Kaitaisha, and I stayed in the country for the next five years. During this period, I toured internationally in all of Kaitaisha's productions, performed a play in Japanese in Tokyo and Kyoto, made a solo production in Tokyo, completed an MA at the University of Melbourne and spent two years in research at the University of Tokyo. In 2006 I returned to Australia, where I enrolled as a $\mathrm{PhD}$ candidate at the University of Melbourne. My research now is partially practicebased and focuses on several aspects of the body of work of three Japanese avant-garde theatre and performance artists in the twentieth century and the present. I am deeply interested in the continuing development of cross-cultural collaborations between artists from Australia and Japan.

This essay is a brief examination of Sakate Yōji's theatre production of The Attic, a work which received its Australian premiere at NIDA in March 2006, and with which I was involved as interpreter. Written and directed by Sakate, The Attic was performed and produced with great enthusiasm and commitment by final-year acting students and first- and second-year technical students, and played to a full house for the two-week season.

In this essay I briefly introduce Sakate's theatrical influences and his background with his company, Rinkōgun, examine the main themes explored in The Attic and engage in a discussion of the issues involved in the Australian production.

${ }^{1}$ Hell Bento!, made by Tetrapod for SBS independent. 


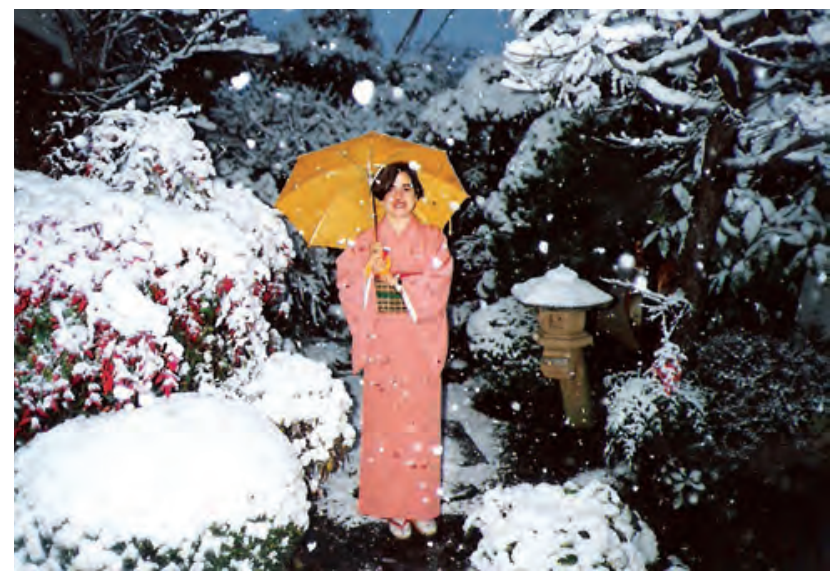

Braving the winter in kimono:

studying chadō at Urasenke (1992-93). 



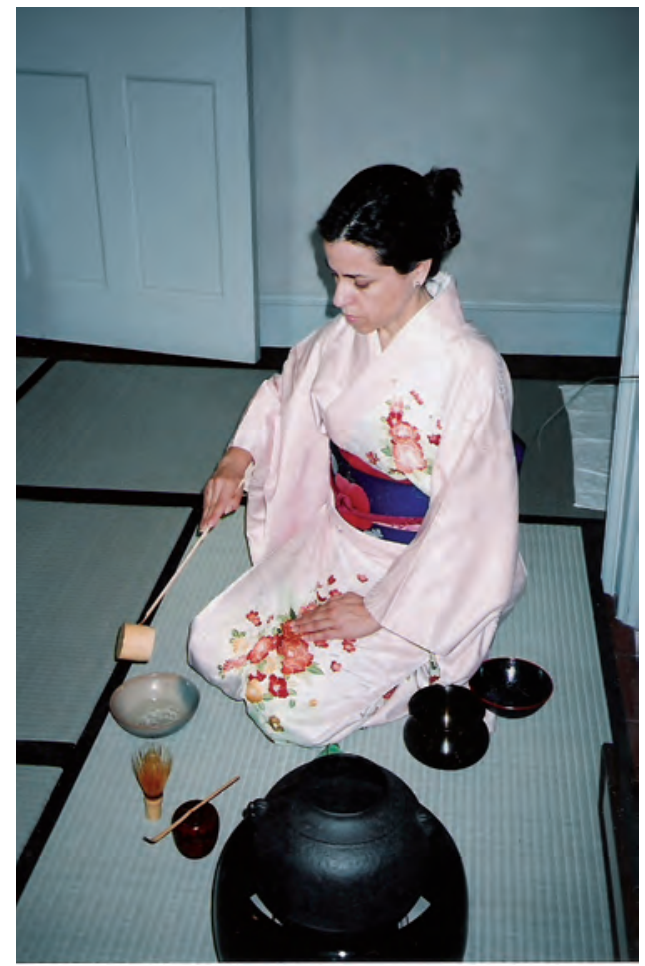

Doing Tea in a chakai in Sydney (2004). 


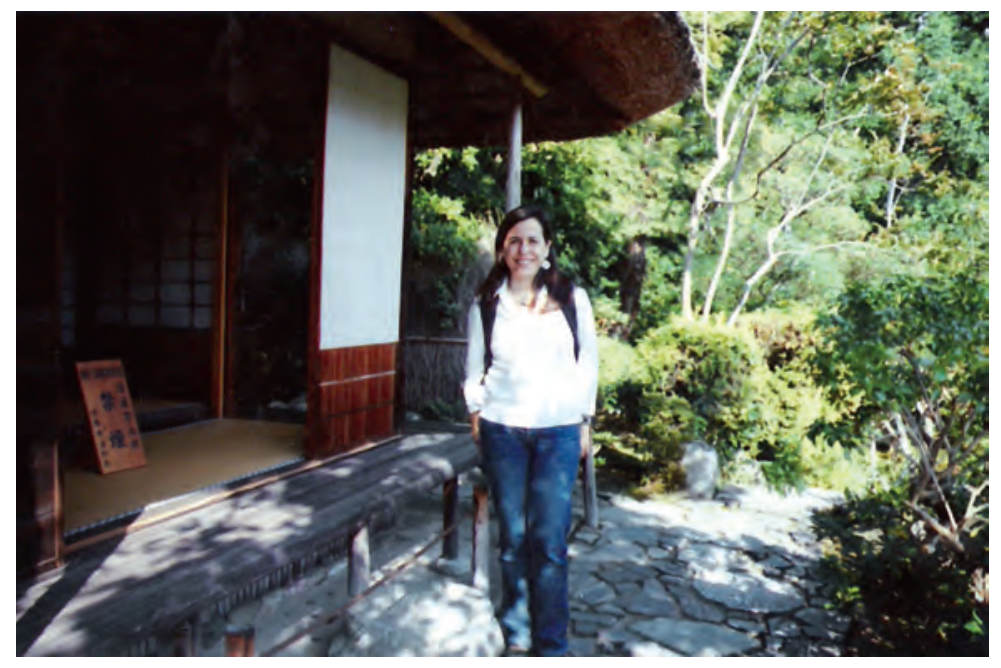

Cristina Rocha next to an historical teahouse in Kyoto (2005). 


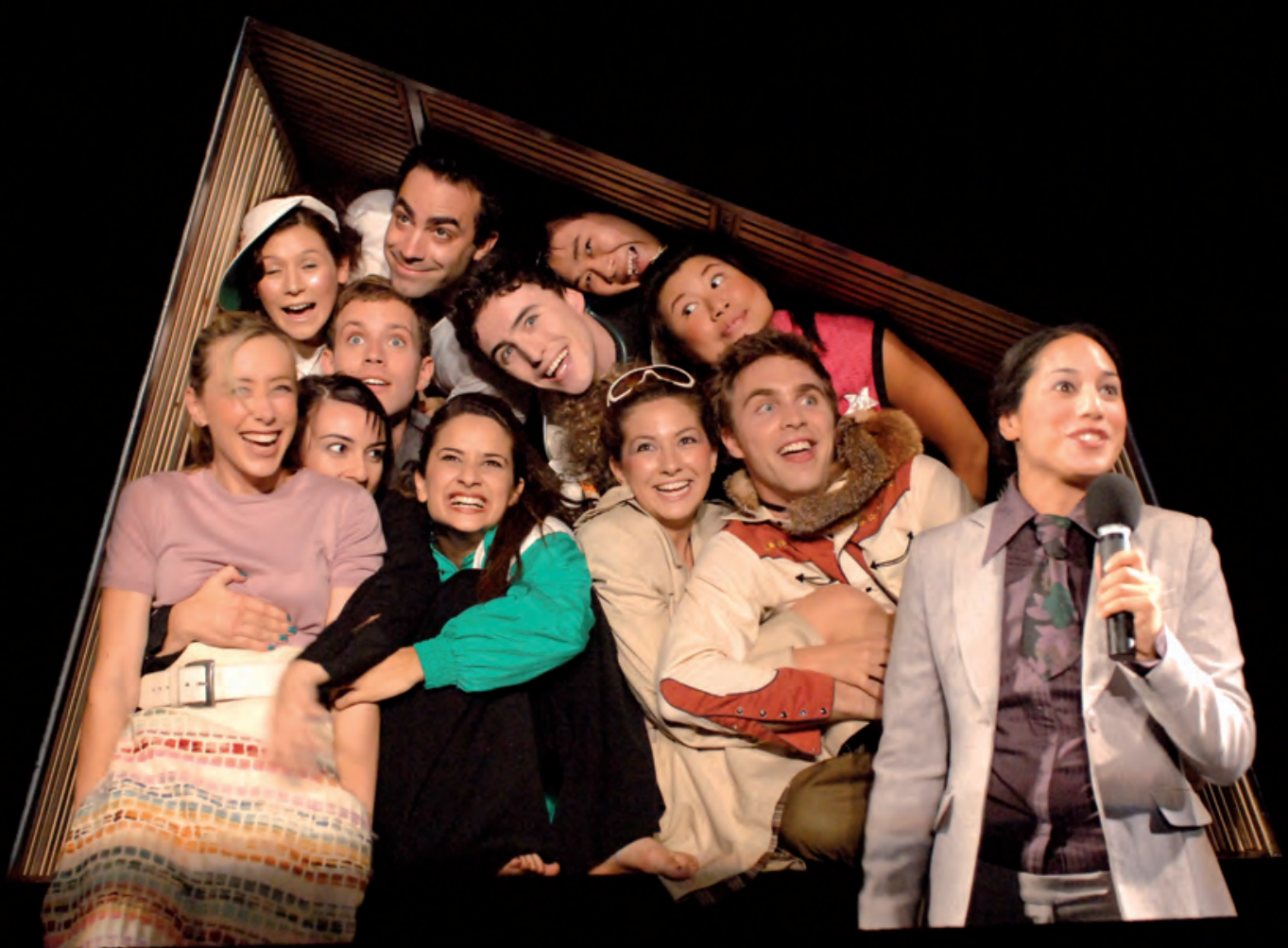

NIDA performance of The Attic. (c) NIDA. Photograph by Branco Gaica. 


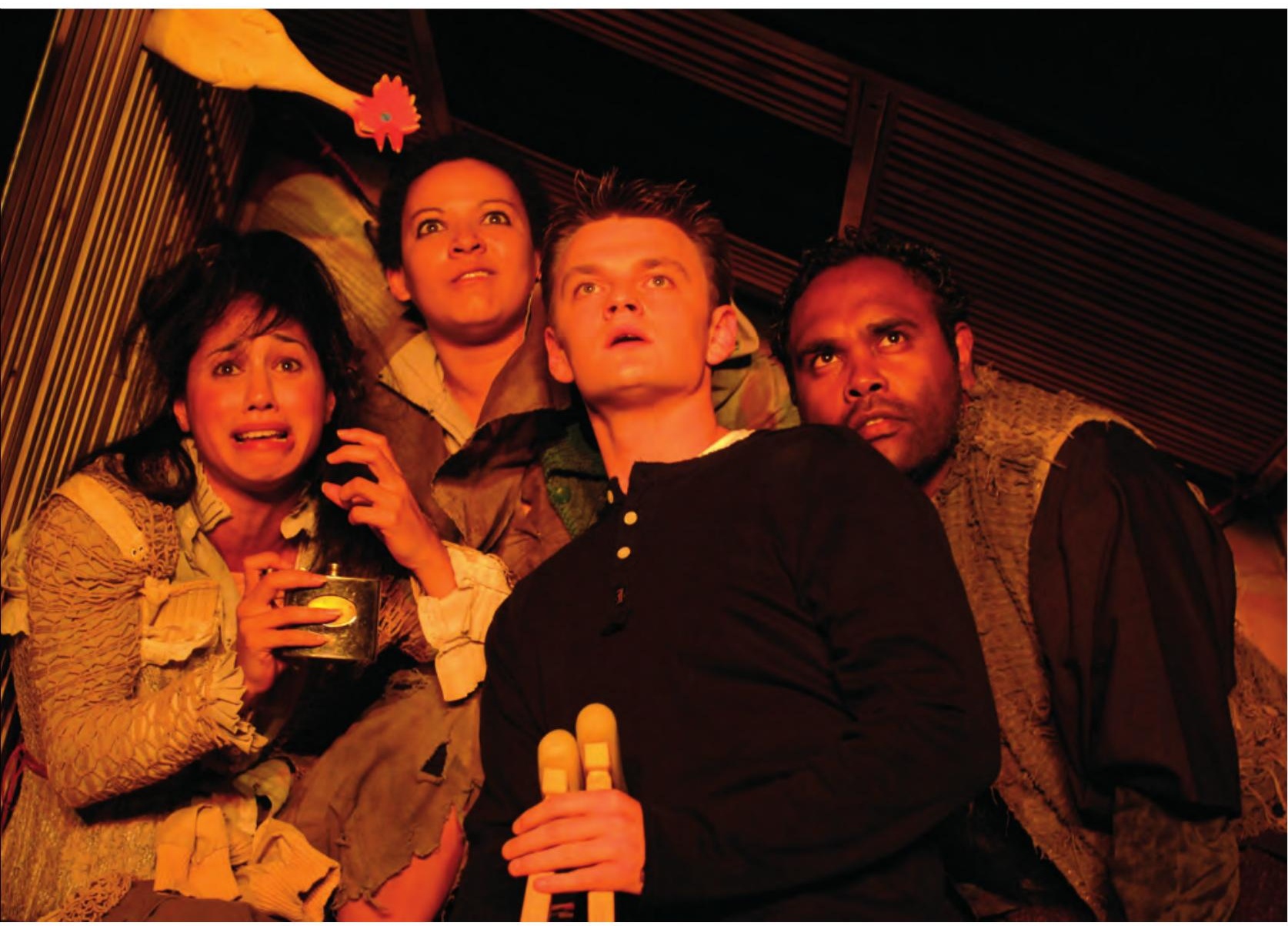

NIDA performance of The Attic. (C) NIDA. Photograph by Branco Gaica. 


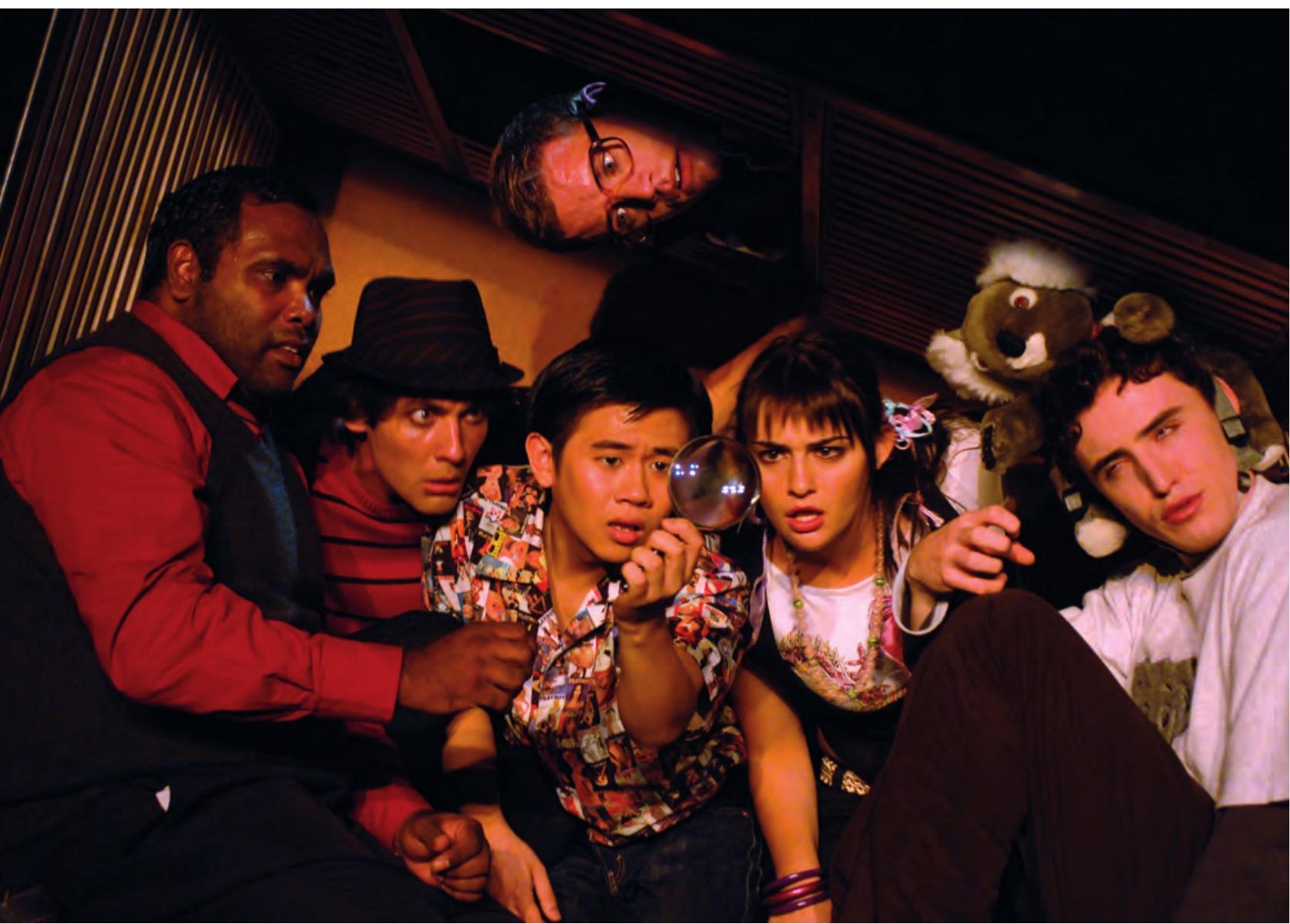

NIDA performance of The Attic. (C) NIDA. Photograph by Branco Gaica. 



\section{The Background}

Sakate Yōji emerged as a theatre maker in the 1980s having been part of the chūkaku (socialist revolutionary) faction of the zengakuren (revolutionary student movement) in the 1970s. He had been strongly influenced by the first generation angura, ${ }^{2}$ an energetic group of theatre practitioners who, as part of the shoggekijo und $\bar{o}^{3}$ had taken back responsibility for the independent management and rights of their theatres. While remaining engaged particularly with European trends in theatre and philosophy, ${ }^{4}$ they re-directed their attention away from the modern realism of shingeki (lit. new theatre) towards re-imagining and invigorating pre-modern and 'Edo period' cultural traditions. Sakate and his generation ${ }^{5}$ enjoyed a boom in small theatre and employed comedy, parody and fantasy in their works. Yet, in the 1990s and despite new government funding infrastructure for the support of new theatre, Sakate's Rinkōgun ${ }^{6}$ were one of the few companies with a public presence to maintain a semblance of angura values in the shögekijo context. Political urgency, social motivation, independence and the desire - and perhaps need - to re-invent Japanese theatre had dissipated. Currently, Sakate balances his company commitments with freelance work for larger companies. Married to an Okinawan and with several Rinkōgun members coming from marginalised backgrounds, his plays are concerned with US bases, ostracism, whaling, the death penalty and land mines.

\section{The Play}

It is no surprise, then, that The Attic depicts a variety of cases of hikikomori (lit. withdrawn, coll. shut-in), ${ }^{7}$ a social phenomenon in Japan where individuals withdraw from society and family and retreat to the confines of their apartments or bedrooms, refusing contact with the outside world for extended periods. ${ }^{8}$ In The Attic, these individuals range from adolescence to middle age.

An attic, cluttered and cramped and filled with old things covered in dust, suggests a space with an unusually charged atmosphere. It is a container crowded with neglected memories, and offers a sense of adventure for children and of nostalgia for

\footnotetext{
${ }^{2}$ The first generation angura were represented by Terayama Shuji (Tenjō Sajiki), Kara Jūrō (Jōkyō Gekijō), Suzuki Tadashi (Waseda Shō Gekijō), Satō Makoto, Kushida Kazuyoshi and Saitō Ren (Engeki Sentaa 68 / 71, synonymously known as Kuro Tento), Ninagawa Yukio, Ōta Shōgo (Tenkei Gekijō) and Betsuyaku Minoru. See Goodman, D., http://www.umich.edu/ iinet/cjs/publications/michclassics/CTJ. $\mathrm{html}$ for further detail. Sakate discussed this at the NIDA visiting artist lecture, February 2006.

${ }^{3}$ The 'small theatre movement'.

${ }^{4}$ For example: Artaud, Meyerhold, Sartre, Beckett, Barthes, Merleau-Ponty, Foucault, Bachelard, Deleuze-Guattari, Benjamin and Greek tragedy had strongly influenced the angura.

${ }^{5}$ For example: Noda Hideki (Yume no yuminsha), Kokami Shoji, Tsuka Kohei. See Pulvers, R., http://www.performingarts.jp/E/art_interview/0601/3.html for further detail.

${ }^{6}$ Others include Hirata Oriza (Seinendan), Shimizu Shinjin (Gekidan Kaitaisha), Miyagi Satoshi (Ku Nảuka), Kawamura Takeshi (Daisan Erotica which has now become T-factory).

${ }^{7}$ Hikikomori is a term first coined by psychologist Saito Tamaki.

${ }^{8}$ The Japanese Ministry of Health stipulates six months of withdrawal as the required time to be considered hikikomori. While their symptoms have ranged widely in popular discourse, there is yet to be consensus on diagnosing hikikomori.
} 
adults. Characters come to this attic to deal with problems, to do business, to negotiate desires, to spy on or hide from others, to liberate imaginations, to reflect and to ask for help.

The Attic is innovatively set within an elevated metal-framed trapezoidal box, like a triangle without the top section. The attic's low, slanting ceiling makes it impossible for actors to stand fully upright, and its narrowness means that it is barely wide enough for someone to lie down. Such a set significantly challenges the actors to concentrate on refining subtlety, stillness, containment, tension and gesture as well as forcing them to ergonomically adjust to a variety of sitting and crawling positions. Supported by metal legs on castors, the raised box is framed within cinema-esque masking panels, and appears to be floating in a void. We follow the attic as it takes on different functions for people in different situations: a cabin in a blizzard; a bunker in a war zone; a stake-out room for detectives; a secret room for samurai to watch their enemies; a coffin buried beneath a house; a collector's item in a department store; an elevator; a cave; a cardboard box for the homeless. By the final scene the surrounding panels are dismantled to reveal the bare-boned metal structure in an exposed theatre studio.

Sakate's objective, while socially critical, is to heal rather than to scald, urging us to confront death and bring change through awareness. Balancing heroism with dysfunctional destructiveness in both genders and diluting the pain of hikikomori reality with humour, he asks the audience to see the complexity of the distinct cases. ${ }^{9}$ His underlying themes are parental responsibility, social and media exploitation and the divisions between adult and child. While the elegiac tone suggests a conclusion to Sakate's journey through myriad small theatres, he also suggests the continued creativity of childhood.

In the following section I address the intercultural nature of the production in Australia.

\section{Australian Hikikomori - Cultural Differences}

Before coming to Australia The Attic received an overseas production with students in the US. Despite this, the difficulties in arriving at a clear and precise understanding of the issues in the play remained significant. While NIDA students were prepared with a translation, related articles, anime and fictional and documentary films on the hikikomori, the play was written for a Japanese audience who are familiar with a social problem which currently (although not exclusively) afflicts society in Japan. It was not that the students were inept at handling the script's multiple situations and temporalities, nor that the struggles encountered with the broad age range of characters were anything

\footnotetext{
${ }^{9}$ Comments made in rehearsal, and artist interview, Performing Arts Network Japan, http://www.performingarts.jp/E/art_interview/0502/1.html, 24th February 2005.
} 
beyond the normal artistic process. Rather, the greatest obstacle the actors faced was the finding of an accurate emotional register in the relationships. Difficulties emerged for the crew, too, in their efforts to meet the exacting technical requirements within the time provided. This was due, obviously, to the lack of a shared language and commonly understood behavioural codes inherent in the words, a crucial factor for theatre makers if they are to arrive at a shared understanding of the intention of the work. A further difficulty lay in Sakate's expectation that actors and crew would think for themselves, quickly utilising their initiative and creativity for character development and set. In short, he wanted them to improvise, which was something with which these students were not so familiar.

While ways of performing codes of status between characters was one area of difference, another area was more practical. Working with students he had never met, without the time to deeply search for implications of language or to develop the students' knowledge of light and sound, Sakate could only work with a shorthand in physical timing and movement. These obstacles, combined with the desire to present a carefully nuanced theatre piece to an unknown Australian audience, made a few very intense weeks for students and Sakate alike.

On the surface, it was the casting that became a random, if not an entirely accidental, key to communicating the play's intentions, while at the same time localising the issues. For example, reductive as it is, three students of darker skin - one of them being the only Aboriginal actor in the year - were cast as the three homeless characters. While the original scene suggests unfair treatment of homeless burakumin ${ }^{10}$ it touched on an equally fraught dimension relevant to local audiences. By contrast, the older brother, the teacher and the young girl - the three characters with whom the audience are supposed to identify, attribute authority or sympathise - were the whitest and blondest actors. Redressing the balance, the Aboriginal actor also played the father, another of the actors who played a homeless person also played the newsreader and all actors participated in the group scenes. After all, the play was written as an ensemble piece. The actors showed subtlety and skill in deliberately playing with these issues of identity through accents and stereotypes, naming their differences and making the representations resonate with their own diverse heritages, which in turn reflected the local terrain and signified problems the audience could engage with.

As Sakate wanted to remain as close to the original as possible, there were jarring moments of incongruence, such as the repeated line 'Japan will be ruined', or the ojigi-style ${ }^{11}$ bow at the end of the young girl's monologue. The students' choice of hymn in the coffin scene as the 1950s tune Happy Days, reminiscent of carefree youth growing up in postwar USA and popular in Australian youth culture, brought a strange irony to

\footnotetext{
${ }^{10}$ Traditional outcasts or untouchables in Japanese society, a term which Sakate used in rehearsal.

${ }^{11}$ A formal bow.
} 
the scene, as well as suggested a conflict between popular (secular) and traditional (religious) mores. The two actors playing the duo roles of mediated Japanese masculinity - samurai, detective and soldier - drew from a ubiquitous popular culture: Kurosawa films; the Monkey television series; and Brokeback Mountain which had just won an Academy Award.

The Attic resonates across cultural borders with regard to life in advanced post-industrial nations, where it is increasingly possible to spend more time living in solitude and venturing into the fantasy worlds of 'borderless' media environments. It suggests the necessity to re-think the core values by which we live in these societies, and the dire need to problematise the politics of exclusion. While the reifying tendencies of packaging and selling hikikomori as 'J-lifestyle'12 perhaps signifies an orientalist perspective being reexported to Western markets, ${ }^{13}$ through a sense of parody this issue has been reflexively posited in the play and further underlined in its re-staging at NIDA.

The undeniable importance of producing The Attic and other contemporary theatre in a prominent Australian theatre institution demonstrates the effectiveness of the continuing challenge to the traditional policy of exclusively teaching the canon of modern Australian and European drama, and the ongoing transition of Australian society. How Australian theatre-makers work with cultural material from local indigenous nations and from cultures in the Asian region will ultimately depend on their continuation to do so. Similarly, for Japanese theatre makers like Sakate, the satisfaction of seeing a production performed beyond its intended context, and the stimulation from its misunderstanding or re-interpretation is undoubtedly rewarding. Then, if the interest is there, the infinitely meticulous work of deciphering and determining interpretations and subjective responses can begin.

Although too early to identify outcomes, the NIDA students were stimulated by and benefited from their intensive time in The Attic. Having now travelled through the many worlds of subsequent productions, they are soon to graduate; but the impact of this production will no doubt germinate beneath the surface and possibly flower in further searches for meaning in unfamiliar worlds.

\section{References}

Goodman, D., Concerned Theatre Journal. Retrieved 20 June 2006, from http://www.umich.edu/ iinet/cjs/publications/ michclassics/CTJ.html .

Iwabuchi, K., 'Complicit exoticism: Japan and its other, Critical Multiculturalism', in Tom O’Regan (ed), Continuum: The Australian Journal of Media \& Culture, vol. 8 no. 2, 1994.

\footnotetext{
${ }^{12}$ Suga Hidemi, 'Lecture at Laokoon Festival', 2005; Uchino T., 'Fukanosei no jidai no Engeki (2)', 2005, pp. 180-194.

${ }^{13}$ Iwabuchi K., 'Complicit exoticism: Japan and its other', 1994, p. 51.
} 
Pulvers, R., Artist Interview: Sakate Yōji. Retrieved 30 June 2006, from http://www.performingarts.jp/E/art_interview/0502/1.html .

- The woman who wants others to sit up and take notice, Artist Interview, The Japan Foundation Performing Arts Network Japan. Retrieved 20 February 2006, from http://www.performingarts.jp/E/art_interview/0601/3.html .

Suga, H., Lecture at Laokoon Festival: 1968 as a turning point for today - its revolutionary and anti-revolutionary vector. Retrieved 7 July 2005, from Kinki University Humanities Website.

Uchino, T., 'Fukanosei no jidai no Engeki (2): J to iu basho, to kindai geijutsu to iu seido ni tsuite', in Butai Geijutsu, (vol. 9), Kyoto University Performing Arts Centre, School of Art and Design 2005, pp. 180-194. 